\title{
Accessibility experiences and the hindsight bias: I knew it all along versus it could never have happened
}

\author{
LAWRENCE J. SANNA \\ University of North Carolina, Chapel Hill, North Carolina \\ NORBERT SCHWARZ \\ University of Michigan, Ann Arbor, Michigan \\ and \\ EULENA M. SMALL \\ University of North Carolina, Chapel Hill, North Carolina
}

\begin{abstract}
In two experiments, we tested accessibility experiences versus accessible content in influencing the hindsight bias when participants generated either thoughts about alternative outcomes or thoughts about known outcomes. Participants who had listed many thoughts (Experiment 1) and those who had contracted their brow muscles (Experiment 2) when considering alternate outcomes rated the known outcome as more likely than did than those who had listed two thoughts or who had not contracted their brows-a "backfire" effect. In contrast, but no less ironically, participants who had listed many thoughts and those who contracted their brows when considering known outcomes rated those outcomes as less likely — an "it could never have happened" effect. Both effects are due to subjective accessibility experiences, and their role in influencing and debiasing the hindsight bias is discussed.
\end{abstract}

We are all wiser in hindsight. As Fischhoff (1982a) observed, after learning event outcomes, people "not only tend to view what has happened as having been inevitable, but also tend to view it as having been 'relatively inevitable' before it happened" (p. 428). They believe that they, and others, should have been able to anticipate the event and may even "misremember their own predictions so as to exaggerate in hindsight what they knew in foresight" (Fischhoff, 1982a, p. 428). This hindsight bias may give us the illusion that we "understand what the past was all about," and may "prevent us from learning anything" from that past (Fischhoff, 1982b, p. 343).

Initially documented by Fischhoff (1975; Fischhoff \& Beyth, 1975), the hindsight bias is a robust phenomenon that has been obtained in varied domains, such as medical diagnoses (see, e.g., Arkes, Wortman, Saville, \& Harkness,

\footnotetext{
This research was supported in part by a Mason and Linda Stephenson Faculty Award and a Junior Faculty Development Award to L. J. S. from the University of North Carolina at Chapel Hill, as well as by a fellowship from the Center for Advanced Study in the Behavioral Sciences to N. S. We thank Chul Shin for assistance with the data collection in Experiment 1, Cheryl Dickter and Eric Gadol for posing in the contractedbrow photos used in Experiment 2, and the Imagination, Goals, and Affect (IGoA, or "ego") lab group at the University of North Carolina at Chapel Hill for comments on this research. Correspondence concerning this article should be addressed to L. J. Sanna, Department of Psychology, CB\# 3270 Davie Hall, University of North Carolina at Chapel Hill, Chapel Hill, NC 27599-3270(e-mail: sanna@unc.edu;Web: http://www. unc.edu/ sanna/).
}

1981; Detmer, Fryback, \& Gassner, 1978), legal judgments (see, e.g., Kamin \& Rachlinski, 1995; LaBine \& LaBine, 1996; Rachlinski, 2000), election results (see, e.g., Leary, 1982; Powell, 1988), sporting events (see, e.g., Leary, 1981), and labor disputes (see, e.g., Mark \& Mellor, 1991; see Christensen-Szalanski\& Willham, 1991, and Hawkins \& Hastie, 1990, for reviews). In all of these domains, event outcomes have been judged more likely when judgments are made from the perspective of hindsight rather than under the uncertainty of foresight.

To account for this, Fischhoff (1975) suggested, "the retrospective judge attempts to make sense, or a coherent whole, of all that he knows about the event" (p. 297). Judges update their mental models of events in light of outcome information, elaborate causal links that might have led up to the event, and de-emphasize information that seems irrelevant in light of the outcome (see Hawkins \& Hastie, 1990). When later asked to report the expectations that they had had prior to knowing the outcome, judges draw on the updated mental model to "rejudge" the event, resulting in the hindsight bias (see Wasserman, Lempert, \& Hastie, 1991, for empirical support). As Hawkins and Hastie (1990, p. 322) noted, this analysis "is consistent with most of the empirical findings" and portrays "hindsightbiases as a side effect of an adaptive learning process." 1

\section{Debiasing hindsight by thinking about alternatives}

The most frequently recommended remedy for debiasing hindsight is "to force oneself to argue against the in- 
evitability of the reported outcome, that is, to try to convince oneself that it might have turned out otherwise" (Fischhoff, 1982b, p. 343). Doing so would presumably counteract the dominance of outcome-supporting cognitions in the updated mental model, helping to restore the original foresight perspective. Empirically, thinking about alternatives has been found to attenuate hindsight biases, but not fully eliminate them (e.g., Arkes, Faust, Guilmette, \& Hart, 1988; Koriat, Lichtenstein, \& Fischhoff, 1980; Slovic \& Fischhoff, 1977). Even worse, we observed in recent research (Sanna \& Schwarz, in press; Sanna, Schwarz, $\&$ Stocker, 2002) that this usually recommended strategy can backfire under some conditions, leaving people all the more convinced that the event was inevitable.

Sanna et al. (2002) presented participants with a description of the British-Gurkha war (adapted from Fischhoff, 1975) and informed them that the British (or the Gurkhas, respectively) had ultimately won. Subsequently, the participants were asked to generate either 2 or 10 thoughts about how the war could have turned out otherwise. Generating only 2 thoughts about alternative outcomes was experienced by the participants as easy and resulted in a small attenuation of the hindsight bias. In contrast, generating 10 thoughts about alternative outcomes was experienced by the participants as difficult and resulted in a significant increase in the size of the hindsight bias. That is, trying to generate many reasons for a different outcome only served to convince the participants all the more that the obtained outcome was inevitable.

Theoretically, these findings suggest that any thoughtgeneration task renders two distinct sources of information accessible: the reasons generated (accessible content) and the ease or difficulty with which these reasons are brought to mind (subjective accessibility experiences). As numerous studies have demonstrated (see Schwarz, 1998, for a review), the implications of accessible content are qualified by accompanying accessibility experiences. Finding it difficult to generate many reasons or to recall many examples, people conclude that there must not be many reasons (or examples), or else it would not be so difficult to bring them to mind. As a consequence, judgments are consistent only with what comes to mind when information comes to mind easily. When recall or generation is difficult, however, judgments are opposite to the implications of accessible content (see, e.g., Schwarz et al., 1991). This observation is consistent with Tversky and Kahneman's (1973) availability heuristic, which proposes that people judge the frequency, probability, and typicality of events by the ease with which examples are brought to mind (see Schwarz \& Vaughn, 2002, for an elaboration).

If this interpretation of the backfire effects observed by Sanna et al. (2002) is correct, generating many alternatives to the known outcome should not increase hindsight biases when the informational value of the experienced difficulty is called into question. Misattributionexperiments reported by Sanna and Schwarz (in press) supported this prediction, in consistency with other research demonstrating that various (mis)attribution manipulations can eliminate the impact of accessibility experiences by undermining their informational value (see, e.g., Haddock, Rothman, Reber, \& Schwarz, 1999; Schwarz et al., 1991; Winkielman, Schwarz, \& Belli, 1998).

In combination, these finding highlight the critical role of metacognitive processes in influencing the hindsight bias: Far from drawing only on accessible content, people also consider the ease or difficulty with which this content could be brought to mind as a source of information in its own right. Hence, thoughts about alternative outcomes can attenuate the hindsight bias when they are easy to bring to mind, but actually increase the hindsight bias when they are difficult to bring to mind, unless the informational value of the accessibility experience is undermined through misattribution or other manipulations.

\section{The present research}

The present experiments extend the theoretical implications of this line of reasoning in several ways. First, using Fischhoff's (1982a, 1982b) recommendations as a starting point, our prior research focused on thinking about alternative outcomes as a debiasing strategy (Sanna \& Schwarz, in press; Sanna et al., 2002). However, the backfire effects observed in our experiments suggest an alternative —and at first apparently paradoxical — way to debias the hindsight bias, which runs counter to Fischhoff's recommendations. If people conclude from the difficulty of generating reasons for alternate outcomes that the known outcome was inevitable, we may be able to attenuate hindsight biases by asking people to generate many reasons favoring the occurrence of the known outcome. Finding it difficult to generate many reasons that favor the known outcome, people may conclude that there are not many, resulting in a reduction of the hindsight bias. This as yet untested strategy is an attempt to turn the metacognitive (accessibility) mechanisms that limit Fischhoff's recommendationsinto an alternative debiasing procedure. Both of the present experiments provide demonstrations of this strategy and test its effectiveness.

Second, in all of our prior debiasing experiments, we manipulated the participants' accessibility experiences by asking them to generate either few or many thoughts. This reliance on a single manipulation can raise concerns about the methods and specificity of our findings. To address these concerns, the participants in Experiment 2 were asked to generate the same number of thoughts, and their subjective accessibility experiences were instead manipulated through proprioceptive bodily feedback. Strack and colleagues (e.g., Stepper \& Strack, 1993; Strack \& Neumann, 2000) successfully demonstrated that contracting the corrugator muscle (resulting in a furrowed brow) is associated with the subjective experience of mental effort (Stepper \& Strack, 1993; Strack \& Neumann, 2000). For example, Stepper and Strack had participants either contract the corrugator muscle or not contract it, while listing five examples of their own assertive or unassertive behavior. Participants who had not contracted the corrugator muscle judged themselves more assertive after listing as- 
sertive rather than unassertive behaviors; in contrast, participants who had contracted the corrugator muscle, leading to feelings of high mental effort, judged themselves less assertive after recalling instances of assertive rather than unassertive behavior. These findings parallel those of Schwarz et al. (1991) for participants who had to list either a few or many examples of assertive or unassertive behaviors, respectively.

In sum, we predict that generating many thoughts about alternative outcomes will increase the hindsight bias, as has been observed in earlier experiments (Sanna \& Schwarz, in press; Sanna et al., 2002). However, extending prior research, we further predict that generating many thoughts favoring known outcomes may reduce the hindsight bias, in contrast to what may be commonly anticipated (see, e.g., Fischhoff, 1982a, 1982b). Finally, we predict that the effects of contracting the corrugator muscle will parallel the effects of listing many thoughts, resulting in (1) increased hindsight bias when thoughts pertain to alternate outcomes, but (2) decreased hindsight bias when thoughts pertain to known outcomes. A consistent pattern of findings when few as opposed to many thoughts are generated (Experiment 1) and when facial expression is manipulated while number of thoughts is held constant (Experiment 2) would provide further support for the role of accessibility experiences in hindsight biases and for the underlying theoretical rationale.

\section{EXPERIMENT 1 Alternate Versus Favoring Outcomes}

Participants read about the British-Gurkha war (Fischhoff, 1975) and were told that the British had won. To manipulate accessibility experiences, the participants listed either 2 (easy) or 10 (difficult) "things that you think helped the British win this war" or "things you think might have helped the Gurkhas win the war instead." If retrospective likelihood judgments are based primarily on accessible content, as Fischhoff's (1982a) recommendation presumes, generating 10 thoughts about the alternate outcome should attenuate the hindsight bias more than generating merely 2 thoughts. But if conclusions drawn from accessible content qualify accompanying accessibility experiences, we should observe an increased hindsight bias when many alternatives are generated, in replication of earlier findings (Sanna et al., 2002). More important, the reverse predictions hold when participants list reasons favoring the known outcome. That is, generating many reasons for the obtained outcome should increase hindsight bias if judgments are based solely on accessible content, but should decrease hindsight bias if conclusions drawn from accessible content are qualified by the subjective experience that doing so is difficult.

These manipulationsresult in a 2 (thoughts-listing: 2 vs. 10) $\times 2$ (thoughts-focus: British vs. Gurkha) betweensubjects factorial design. We added a nonfactorial control group in which the participants received outcome knowledge but did not list any thoughts. Our predictions call for an interaction between number of thoughts listed and thoughts-focus.

\section{Method}

\section{Participants}

Seventy-two introductory psychology students participated for extra course credit and were randomly assigned to conditions.

\section{Procedure}

The participants received a questionnaire entitled "Social Judgments" during a regularly scheduled class session, and read the following scenario, adapted from Fischhoff (1975):

\begin{abstract}
For some years after the arrival of Hastings as Governor-General of India, the consolidation of power involved serious war. The first of these wars took place on the northern frontier of Bengal where the British were faced by plundering raids of the Gurkhas of Nepal. Attempts had been made to stop raids by an exchange of lands, but the Gurkhas would not give up their claims to country under British control, and Hastings decided to deal with them once and for all. The campaign began in November, 1814. It was not glorious. The Gurkhas were only some 12,000 strong; but they were brave fighters, fighting in a territory well-suited to their raiding tactics. The older British commanders were used to war in the plains where the enemy ran away from a resolute attack. In the mountains of Nepal it was not easy even to find the enemy. The troops and transport animals suffered from the extremes of heat and cold, and the officers learned caution only after sharp reverses. Major-General Sir D. Octerlony was the one commander to escape from these minor defeats. The British overcame the Gurkhas and ultimately won the war. ${ }^{2}$
\end{abstract}

Thoughts-listing and thoughts-focus. In a 0 -thoughts control condition, the participants did not list any thoughts. All the participants in each of the four thoughts-listing conditions read, "We are interested in your thoughts about this war." In the British thoughtsfocus condition, the instructions continued as follows: "Please list $[2,10]$ things that you think helped the British win this war." In the Gurkha thoughts-focus condition, the instructions continued as follows: "Please list $[2,10]$ things that you think might have helped the Gurkhas win the war instead." Thus, within thoughts-focus, statements varied only by whether the participants provided 2 (2thoughts condition) or 10 (10-thoughts condition) thoughts.

Probability judgments. All the participants were asked, "If we hadn't already told you who had won, what would you have thought the probability of the British winning would be? In an answer ranging from $0-100 \%$, estimate the probability that the British could have won the war." A space was provided in which open-ended responses were supplied by the participants.

Subjective difficulty. Finally, the participants in each thoughtslisting condition rated the degree to which they had found it difficult to list thoughts by answering the following question: "To what degree did you find it difficult to list thoughts about the [British, Gurkhas] winning the war? $(1=$ very easy to $7=$ very difficult $)$."

All the participants were thanked and debriefed.

\section{Results and Discussion}

We conducted $2 \times 2$ analyses of variance (ANOVAs) with simple effect tests on the factorial portion of the data. Comparisons with the 0 -thoughts control condition were made using the Dunnett procedure (see Winer, Brown, \& Michels, 1991).

\section{Thought Listing and Subjective Difficulty}

The participants assigned to the 2-thoughts condition listed 2 thoughts $(M=2.00, S D=0.00)$, whereas those in the 10-thoughts condition listed a mean of 8.17 thoughts $(S D=2.58)$. Examples of thoughts listed were as follows: 
"The British had more experience and larger numbers," and "The Gurkhas could have sought to form alliances with different groups or countries." A $2 \times 2$ ANOVA $\left(M S_{\mathrm{e}}=2.14\right)$ indicated that the participants in the 10thoughts condition rated this task as more difficult $(M=$ $6.01, S D=0.89)$ than did those in the 2-thoughts condition $[M=3.48, S D=1.42 ; F(1,53)=38.20, p<.01]$. Our manipulations were therefore effective.

\section{Probability Judgments}

A $2 \times 2$ ANOVA $\left(M S_{\mathrm{e}}=318.16\right)$ revealed a thoughtsfocus main effect $[F(1,53)=7.05, p<.01]$, qualified by a thoughts-focus $\times$ thoughts-listing interaction $[F(1,53)=$ $19.44, p<.01$; see Table 1]. When the participants had to list thoughts about alternatives, the judgments replicated the previously obtained pattern (Sanna et al., 2002). That is, the participants who were asked to think of 10 ways that the Gurkhas might have won the war viewed a British victory as more likely than did those asked to think of only 2 ways [simple effect $F(1,26)=6.61, p<.05$ ]. This pattern reversed, however, when the participants were asked to think about factors that contributed to the obtained outcome. In this case, the participants who were asked to think of 10 things that helped the British win the war actually viewed this outcome as less likely than did those asked to think of two ways [simple effect $F(1,27)=13.25$, $p<.01]$. Additional comparisons with the 0 -thoughts control condition [Dunnett $F(4,67)=8.61, M S_{\mathrm{e}}=309.06$, $p<.01]$ revealed that the participants who generated 10 thoughts about a Gurkha (or British) victory considered a British victory more (or less, respectively) likely than did the control participants $[F \mathrm{~s}(1,27)>5.79, p \mathrm{~s}<.05]$.

\section{Discussion}

In sum, the participants who thought of many ways that the Gurkhas might have won the war considered this alternate outcome less likely, and a British victory more likely, than did those who thought of only a few ways. Similarly, the participants who thought of many ways that may have helped the British win the war considered this obtained outcome less likely than did those who thought of only a few ways. In both cases, the participants concluded from the experienced difficulty of thought generation that there could not be many such ways, as is reflected in their respective probability judgments. When their thoughts pertained to alternate outcomes, the result was an increased hindsight bias, replicating the "backfire" effect observed earlier (Sanna \& Schwarz, in press; Sanna et al., 2002); but when their thoughts pertained to the obtained outcome, the result was a decreased hindsight biasa previouslyundocumented "it-could-never-have-happened" effect.

Correlational analyses support this interpretation. When the participants' thoughts pertained to a Gurkha victory, the actual number of thoughts listed correlated positively with the judged likelihood of a British victory $[r(26)=.47]$; conversely, the same correlation was negative $[r(27)=$ $-.44]$ when the participants' thoughts pertained to a British victory (both $p s<.05$ ). Moreover, correlations between the participants' subjective difficulty ratings and their probability judgments revealed the same pattern [British $r(27)=-.68, p<.01 ;$ Gurkha $r(26)=.33, p=.08$ ]

\section{EXPERIMENT 2 \\ Facial Expression and Subjective Difficulty}

Experiment 2 extended Experiment 1 in several ways. In Experiment 1, inferences about the hindsight bias were limited to comparisons with a 0 -thoughts control condition, in which the participants were given outcome information but did not generate thoughts. In Experiment 2, we included an additional no-outcome control condition, in which the participants were not given any outcome information and did not list any thoughts. These two control conditions allow a better understanding of the emerging hindsight bias and its reduction.

More importantly, we held the number of thoughts listed constant at five ${ }^{3}$ and manipulated the participants' experienced ease or difficulty of thought generation by inducing some of them to contract the corrugator (brow) muscle. Contracting corrugator muscles is associated with effortful actions and induces the experience of difficulty, resulting in effects parallel to generating many thoughts (see, e.g., Stepper \& Strack, 1993; Strack \& Neumann, 2000). The main design was a 2 (facial expression: control vs. tensed) $\times 2$ (thoughts-focus: British vs. Gurkha) betweensubjects factorial. In addition, we included two nonfactorial control conditions, in which the participants received outcome knowledge but listed no thoughts (0-thoughts) or received no outcome knowledge to begin with (no-

Table 1

Mean Probability Judgments (in Percentages) by Thoughts-Listing and Thoughts-Focus and Nonfactorial Control for Experiment 1

\begin{tabular}{|c|c|c|c|c|c|c|c|c|c|}
\hline \multirow[b]{3}{*}{ Thoughts-Focus } & \multicolumn{6}{|c|}{ Thoughts-Listing } & \multirow{2}{*}{\multicolumn{3}{|c|}{$\begin{array}{c}\text { Nonfactorial Control } \\
\text { 0-Thoughts }\end{array}$}} \\
\hline & \multicolumn{3}{|c|}{ 2-Thoughts } & \multicolumn{3}{|c|}{ 10-Thoughts } & & & \\
\hline & $M$ & $S D$ & $\bar{n}$ & $M$ & $S D$ & $\bar{n}$ & $M$ & $S D$ & $n$ \\
\hline British & 59.66 & 19.31 & 15 & 33.57 & 19.25 & 14 & & & \\
\hline Gurkha & 51.07 & 17.99 & 14 & 71.07 & 14.16 & 14 & & & \\
\hline
\end{tabular}

Note-All the participants were told that the British had won. A British thoughts-focus thus represents thoughts about the same outcome; a Gurkha thoughts-focus represents thoughts about a different outcome. Nonfactorial 0 -thoughts control participants did not list any thoughts. 
outcome). We predicted that facial expression manipulations would replicate the pattern observed in Experiment 1 when number of thoughts was held constant. This would further corroborate the hypothesis that our findings are due to subjective accessibility experiences, rather than to possibly unidentified differences in thought generation.

\section{Method}

\section{Participants}

One hundred one introductory psychology students participated for extra course credit, and were randomly assigned to conditions.

\section{Procedure}

The procedures of Experiment 2 were similar to those of Experiment 1 , with the exceptions noted below. The participants reported to the laboratory for a study called "Evaluating Military Tactics," and the experiment was run by computer. Upon arrival, the participants were seated in individual rooms and read the following instructions:

Welcome to the experiment. We are studying a variety of factors that might contribute to people's performances and decision making when working on computers. In this particular experiment, we are interested in people's judgments of events. You will be given a brief story to read, and you will be asked to answer some questions about the story.

The participants pressed a key to continue. On the next screen, they were instructed to read a story about military tactics and were informed that they could take as much time as they liked to read and understand the story. The story was about the British-Gurkha war and was almost identical to that used in Experiment 1, the one exception being that the participants in the no-outcome control condition were not provided with the final sentence stating that the British had ultimately won the war.

Facial expression. After reading the scenario, facial expression was varied. Manipulations were modeled after prior research (Stepper \& Strack, 1993; Strack \& Neumann, 2000). In the tensed facial expression conditions, the participants read:

We are interested in the tension that can be caused by working on a computer. In order to test this, we have therefore developed a method to find out if people are prone to tenseness caused by this type of work. We would like you to simulate tension by making the facial expression depicted below.

Two photos, one of a female and one of a male, were shown with the subjects' contracted brow muscles clearly visible and an arrow on each photo pointing to their contracted brows. In addition to viewing these photos, the participants were told further:

To make this face, you should contract your brow by moving your eyebrows toward the center of your forehead as depicted in the photographs. When you have arranged your face in this way, you may continue. However, it is important that you keep your face arranged in this way until we instruct you to stop (which we will do later on).
In the control facial condition, the participants were not asked to make any expression while listing thoughts, nor did they engage in any facial expressions in the 0-thoughts or no-outcome control conditions.

Thoughts-focus. In the respective conditions, thoughts about either a British win (British focus) or a Gurkha win (Gurkha focus) were solicited with instructions identical to those of Experiment 1, except that each of the participants was asked to list five thoughts. The participants in the tensed-face conditions were reminded that they should "maintain the facial expression while listing thoughts." In the 0-thoughts control condition, identical to that used in Experiment 1 , and in the no-outcome control condition, the participants did not list any thoughts. The participants typed thoughts into blank spaces on the screen using the computer keyboard.

Probability judgments. As we have described, no outcome was provided in the no-outcome control condition, and probabilities were solicited as follows: "In an answer ranging from 0 to $100 \%$, estimate the probability that the [British, Gurkhas] will ultimately win the war." All the other participants were given an outcome, identical to that of Experiment 1, and probability judgments were solicited with instructions identical to those used in that experiment. The participants in the tensed-brow conditions were told to discontinue the facial expression before making judgments. The participants typed probabilities into a blank space on the computer screen.

All of the participants were debriefed and thanked.

\section{Results and Discussion}

The data were analyzed similarly to those of Experiment 1 .

\section{Thought Listing and Subjective Difficulty}

All the participants in the factorial portion of the design were asked to list five thoughts. A $2 \times 2 \operatorname{ANOVA}\left(M S_{\mathrm{e}}=\right.$ $0.43)$ revealed that these participants listed a mean of 4.22 thoughts $(S D=0.67)$, which did not differ by condition (all $\left.F_{\mathrm{s}}<1\right)$. Although the same number of thoughts was listed by both groups, an ANOVA $\left(M S_{\mathrm{e}}=1.50\right)$ indicated that the participants in the tensed-brow conditions perceived the task to be subjectively more difficult $(M=6.03, S D=1.09)$ than did those in the control-face conditions $[M=4.52, S D=$ $1.32 ; F(1,63)=27.48, p<.01]$. Thus, as intended through our manipulations, the participants listed similar numbers of thoughts but experienced this process as differentially difficult, depending on the induced facial expression.

\section{Probability Judgments}

The participants who had received outcome information and listed no thoughts ( 0 -thoughts condition) considered a British victory more likely than did those who had

Table 2

Mean Probability Judgments (in Percentages) by Facial Expression and Thoughts-Focus and Nonfactorial Controls For Experiment 2

\begin{tabular}{|c|c|c|c|c|c|c|c|c|c|c|c|c|}
\hline \multirow[b]{3}{*}{ Thoughts-Focus } & \multicolumn{6}{|c|}{ Facial Expression } & \multicolumn{6}{|c|}{ Nonfactorial Controls } \\
\hline & \multicolumn{3}{|c|}{ Control } & \multicolumn{3}{|c|}{ Tensed } & \multicolumn{3}{|c|}{ 0-Thoughts } & \multicolumn{3}{|c|}{ No-Outcome } \\
\hline & $M$ & $S D$ & $n$ & $M$ & $S D$ & $n$ & $M$ & $S D$ & $n$ & $M$ & $S D$ & $n$ \\
\hline British & 58.53 & 14.34 & 17 & 37.78 & 14.68 & 18 & & & & & & \\
\hline Gurkha & 56.94 & 14.53 & 16 & 68.44 & 13.28 & 16 & 58.53 & 14.12 & 17 & 48.53 & 14.42 & 17 \\
\hline
\end{tabular}

Note-All participants in the facial expression conditions were told that the British had won, and listed five thoughts. A British thoughts-focus thus represents thoughts about the same outcome; a Gurkha thoughts-focus represents thoughts about a different outcome. The nonfactorial 0-thoughts control participants were told that the British had won, but did not list any thoughts. The nonfactorial no-outcome participants were not given any outcome, and they did not list any thoughts. 
received no outcome information $[F(1,33)=4.18, p<.05]$, replicating the basic hindsight effect (Fischhoff, 1975).

More important, a $2 \times 2$ ANOVA $\left(M S_{\mathrm{e}}=202.51\right)$ revealed a thoughts-focus main effect $[F(1,63)=17.43, p<$ $.01]$, qualified by a thoughts-focus $\times$ expression interaction $[F(1,63)=21.46, p<.01 ;$ see Table 2]. As we had predicted, the participants who had tensed their brows while thinking about how the Gurkhas might have won the war viewed a British victory as more likely than did those in the control-face condition [simple effect $F(1,31)=5.46$, $p<.05]$. This finding replicates the backfire effect observed after the participants had listed many alternative thoughts (current Experiment 1; Sanna et al., 2002), but, in the present case, actual thought numbers were held constant. Conversely, the participants who had tensed their brows while thinking about ways that might have helped the British win viewed a British victory as less likely than did those in the control-face condition [simple effect $F(1,34)=17.87, p<.01]$. This replicates the "it-couldnever-have-happened" effect obtained in Experiment 1, but, again, while number of thoughts is held constant.

In addition, the 0 -thoughts control condition was compared with the cells in the factorial portion of the design [Dunnett $\left.F(4,83)=10.74, M S_{\mathrm{e}}=201.85, p<.01\right]$. In consistency with the pattern of Experiment 1, the participants who had tensed their brows while thinking about a Ghurka (or British) victory considered a British victory more (or less, respectively) likely than did those in the 0 -thoughts control condition $[F \mathrm{~s}(1,32$ or 34$)>4.30, p \mathrm{~s}<.05]$. Finally, the no-outcome control condition was also compared with the cells in the factorial portion of the design [Dunnett $\left.F(4,83)=11.12, M S_{\mathrm{e}}=203.60, p<.01\right]$. Again, the participants who had tensed their brows while thinking about a Ghurka (or British) victory considered a British victory more (or less, respectively) likely than did those in the no-outcome control condition $\left[F_{\mathrm{S}}(1,32\right.$ or 33$)>$ $4.77, p s<.05]$.

\section{Discussion}

In sum, Experiment 2 replicates the pattern observed in Experiment 1 while the number of the participants' thoughts was held constant. The participants who had tensed their brows while thinking about a Gurkha victory rated a British victory as more likely than did those who had not tensed their brows, had not listed any thoughts, or had had no outcome knowledge to begin with. Conversely, the participants who had tensed their brows while thinking about a British victory rated this outcome as less likely than did those who had not tensed their brows had not listed any thoughts, or had had no outcome knowledge to begin with. These findings suggest that contracting the corrugator muscles induces a subjective experience of effort, paralleling the phenomenal experience of generating many thoughts (Stepper \& Strack, 1993; Strack \& Neumann, 2000).

Correlational analyses are consistent with this interpretation. When the participants' thought listings pertained to a British victory, they rated such a victory as less likely the more difficult they found the task $[r(33)=-.68, p<.01]$; but when their thought listings pertained to a Gurkha victory, they rated a British victory as more likely the more difficult they found the task $[r(30)=.45, p<.01]$. Note that this pattern was obtained even though all the participants listed similar numbers of thoughts; in fact, actual number of thoughts listed was unrelated to the probability ratings [British $r(33)=.15, p=.36$; Gurkha $r(30)=.007$, $p=.96]$. Instead, the variation in experienced difficulty is primarily due to the manipulation of facial expressions.

Following Strack and colleagues (Stepper \& Strack, 1993; Strack \& Neumann, 2000), we presume that mental effort is associated with corrugator contraction and that this conveys a phenomenal experience of effort. However, several alternative accounts have been suggested. One holds that contracting the corrugator muscle may induce negative mood (see, e.g., Larsen, Kasimatis, \& Frey, 1992), which, in turn, may influence participants' processing style. Although possible in principle, this process would result in the opposite pattern of results. In keeping with the general observation that positive moods foster heuristic processing, whereas negative moods foster systematic processing (Schwarz, 1990, 2002), Ruder and Bless (2002) showed that happy participants are likely to rely on their subjective accessibility experiences, whereas sad participants are likely to rely on accessible thought content. When applied to the present study, reliance on thought content would predict a lower probability judgment of a British win after thinking about a British rather than a Gurkha victory-exactly the opposite of the observed pattern.

A second account holds that furrowing one's brow may be cognitively (or physically) resource consuming, making it more difficult to generate the requested number of thoughts. Empirically, however, facial expression did not influence the number of thoughts listed in Experiment 2. Nevertheless, competing resource demands may contribute to the subjective experience of difficulty that the facial expression elicits. Finally, a third account holds that photos illustrating furrowed brows may prime the concept of effort, resulting in an effect that requires no subjective experience. This account is at odds with the observation that (mis)attribution manipulations reliably eliminate the impact of experienced difficulty (see, e.g., Sanna \& Schwarz, in press; Schwarz et al., 1991; Winkielman et al., 1998). These manipulations undermine the informational value of the subjective experience without affecting the cognitive accessibility of the concept "effort" (see Schwarz, 1998; Schwarz \& Clore, 1996). In sum, none of these alternative explanations provides a parsimonious account for the full set of results.

\section{GENERAL DISCUSSION}

As has been demonstrated by numerous studies, knowing event outcomes reliably produces the impression that those outcomes were relatively inevitable (see Christensen- 
Szalanski \& Willham, 1991, and Hawkins \& Hastie, 1990, for reviews). Hence, people feel that they could have anticipated them all along and erroneously recall or reconstruct that they did, in fact, anticipate them. This hindsight bias can interfere with our ability to learn from the past, because it fosters false confidence in the accuracy of our theories about the world (Fischhoff, 1982b). To counteract the impact of highly accessible outcome information, it may seem useful "to force oneself to argue against the inevitability of the reported outcome, that is, to try to convince oneself that it might have turned out otherwise" (Fischhoff, 1982b, p. 343). As the present research highlights, however, this strategy is far from guaranteeing success. People's subjective accessibility experiences must also be taken into account when they try to predict the effects of thought content on influencing and debiasing the hindsight bias.

The participants who had listed many ways that the British-Gurkha war could have turned out otherwise (Experiment 1) and those who had contracted their corrugator muscles while doing so (Experiment 2) judged the obtained outcome more likely than did those who had listed only two thoughts or who had not contracted their corrugator muscles. These increased hindsight biases were obtained relative to the 0 -thoughts control groups with outcome knowledge (Experiments 1 and 2) and relative to the control group without outcome knowledge (Experiment 2). Quite clearly, attempts to reduce the hindsight bias by asking people to generate reasons for alternative outcomes backfired, as has been observed in earlier experiments (Sanna et al., 2002). In contrast, but no less ironically, the participants who listed many thoughts about factors favoring the known outcome (Experiment 1) and those who had contracted their corrugator muscles while doing so (Experiment 2) actually rated this outcome as less likely, a reverse "it-could-never-have-happened" effect. Again, this reduction was obtained relative to the 0 thoughts control groups with outcome knowledge (Experiments 1 and 2 ) and relative to the control group without outcome knowledge (Experiment 2).

Both the obtained "backfire" and "it-could-never-havehappened" effects are traceable to a common underlying mechanism: people's use of subjective accessibility experiences as a source of information (for reviews, see Schwarz, 1998, and Schwarz \& Vaughn, 2002). Generating many thoughts is difficult, and the experienced difficulty is informative in its own right. In consistency with Tversky and Kahneman's (1973) availability heuristic, people infer from experienced difficulty that the respective reasons are not plentiful; otherwise, thinking of them would not be so difficult. Hence, a difficult search for alternatives leaves people all the more convinced that the obtained outcome was inevitable, whereas a difficult search for reasons favoring a known outcome leaves them feeling that it could never have happened.

We observed parallel effects of varying the number of requested thoughts (Experiment 1) and of induced facial expressions (Experiment 2), in consistency with earlier research (Stepper \& Strack, 1993; Strack \& Neumann, 2000). The participants' ratings of thoughts-listing difficulty were correlated with the size of the hindsight bias (Experiments 1 and 2), even when subjective difficulty was varied by facial expression and the actual number of thoughts generated was held constant (Experiment 2). In other research, Sanna and Schwarz (in press) found that the ironic impact of listing many thoughts is eliminated when participants attribute the accompanying experience of difficulty to another source, so the accessibility experienced is rendered nondiagnostic.In combination, these findings highlight the role of subjective accessibility experiences in the emergence and debiasing of hindsight effects.

Finally, our findings connect with several other areas. Psychologists' common focus on thought content misses the point that thinking is accompanied by various subjective experiences, such as ease of recall or generation (e.g., Schwarz, 1998), perceptual and conceptual fluency (e.g., Jacoby, Kelley, \& Dywan, 1989; Winkielman, Schwarz, Reber, \& Fazendeiro, in press), and affective responses (e.g., Clore, 1992; Schwarz \& Clore, 1996). Each of these areas indicates that subjective experiences are informative in their own right. Research has also shown that mental simulations can be functional or dysfunctional in other domains (see Sanna, 1996, 2000; Sanna, Stocker, \& Clarke, in press; Sanna, Turley-Ames, \& Meier, 1999), and our present findings additionally tie to these areas. Like our present findings, research on the "psychology of memory accuracy" (see Koriat, 1993) also implicates subjective experiences, suggesting that "the quality of phenomenal experience may be critical in leading the rememberer to accept a memory as true" (Koriat, Goldsmith, \& Pansky, 2000, p. 487). In short, judgments depend on people's subjective theories, which are themselves malleable and context dependent (see, e.g., Sanna \& Schwarz, in press; Skurnik, Schwarz, \& Winkielman, 2000; Winkielman \& Schwarz, 2001). Unless these processes are taken into account, many apparently straightforward suggestions may produce surprising results, as the example of debiasing hindsight illustrates.

\section{REFERENCES}

Arkes, H. R, Faust, D., Guilmette, T. J., \& Hart, K. (1988). Eliminating the hindsight bias. Journal of Applied Psychology, 66, 252-254.

Arkes, H. R., Wortman, R. C., Saville, P. D., \& Harkness, A. R. (1981). Hindsight bias among physicians weighing the likelihood of diagnosis. Journal of Applied Psychology, 66, 584-588.

Christensen-Szalanski, J. J. J., \& Willham, C. F. (1991). The hindsight bias: A meta-analysis. Organizational Behavior \& Human Decision Processes, 48, 147-168.

Clore, G. L. (1992). Cognitive phenomenology: Feelings and the construction of judgment. In L. L. Martin \& A. Tesser (Eds.), The construction of social judgments (pp. 133-164). Hillsdale, NJ: Erlbaum.

Detmer, D. E., Fry back, D. G., \& Gassner, K. (1978). Heuristics and biases in medical decision making. Journal of Medical Education, 53, 682-683.

ERdFelder, E., \& Buchner, A. (1998). Decomposing the hindsight bias: A multinomial processing tree model for separating recollection 
and reconstruction in hindsight. Journal of Experimental Psychology: Learning, Memory, \& Cognition, 24, 387-414.

FischHoff, B. (1975). Hindsight $\neq$ foresight: The effect of outcome knowledge on judgment under uncertainty. Journal of Experimental Psychology: Human Perception \& Performance, 1, 288-299.

Fischнoff, B. (1982a). Debiasing. In D. Kahneman, P. Slovic, \& A. Tversky (Eds.), Judgment under uncertainty: Heuristics and biases (pp. 422444). New York: Cambridge University Press.

FischHOFF, B. (1982b). For those condemned to study the past: Heuristics and biases in hindsight. In D. Kahneman, P. Slovic, \& A. Tversky (Eds.), Judgment under uncertainty: Heuristics and biases (pp. 332351). New York: Cambridge University Press.

FischHoff, B., \& BeYTh, R. (1975). I knew it would happen: Remembered probabilities of once future things. Organizational Behavior \& Human Performance, 13, 1-16.

Haddock, G., Rothman, A. J., Reber, R., \& Schwarz, N. (1999), Forming judgments of attitude certainty, importance, and intensity: The role of subjective experiences. Personality \& Social Psychology Bulletin, 25, 771-782.

Hawkins, S. A., \& Hastie, R. (1990). Hindsight: Biased judgment of past events after the outcomes are known. Psychological Bulletin, 107, 311-327.

Hoffrage, U., Hertwig, R., \& Gigerenzer, G. (2000). Hindsight bias: A by-product of knowledge updating? Journal of Experimental Psychology: Learning, Memory, \& Cognition, 26, 566-581.

Jacoby, L. L., Kelley, C. M., \& Dywan, J. (1989). Memory attributions. In H. L. Roediger III, \& F. I. M. Craik (Eds.), Varieties of memory and consciousness: Essays in honor of Endel Tulving (pp. 391422). Hillsdale, NJ: Erlbaum.

KAmin, K. A., \& RACHLINSKI, J. J. (1995). Ex post $\neq$ ex ante: Determining liability in hindsight. Law \& Human Behavior, 19, 89-104.

Koriat, A. (1993). How do we know what we know? The accessibility model of feeling of knowing. Psychological Review, 100, 609-639.

Koriat, A., Goldsmith, M., \& Pansky, A. (2000). Toward a psychology of memory accuracy. Annual Review of Psychology, 51, 481-537.

Koriat, A., Lichtenstein, S., \& Fischioff, B. (1980). Reasons for overconfidence. Journal of Experimental Psychology: Human Learning \& Memory, 6, 107-118.

LaBine, S. J., \& LaBine, G. (1996). Determinations of negligence and the hindsight bias. Law \& Human Behavior, 20, 501-516.

Larsen, R. J., Kasimatis, M., \& Frey, K. (1992). Facilitating the furrowed brow: An unobtrusive test of the facial feedback hypothesis applied to unpleasant affect. Cognition \& Emotion, 6, 321-338.

LEARY, M. R. (1981). The distorted nature of hindsight. Journal of Social Psychology, 115, 25-29.

LEARY, M. R. (1982). Hindsight distortion and the 1980 Presidential election. Personality \& Social Psychology Bulletin, 8, 257-263.

Mark, M. M., \& Mellor, S. (1991). Effect of self-relevance of an event on hindsight bias: The foreseeability of a layoff. Journal of Applied Psychology, 76, 569-577.

Powell, J. L. (1988). A test of the knew-it-all-along effect in the 1984 presidential statewide elections. Journal of Applied Social Psychology, 18, 760-773.

RACHLINSKI, J. J. (2000). A positive psychological theory of judging in hindsight. In C. R. Sunstein (Ed.), Behavioral law and economics (pp. 95-115). New York: Cambridge University Press.

RUDER, M., \& BLESS, H. (2002). Mood and the reliance on the ease of retrieval heuristic. Manuscript submitted for publication.

SANNA, L. J. (1996). Defensive pessimism, optimism, and simulating alternatives: Some ups and downs of prefactual and counterfactual thinking. Journal of Personality \& Social Psychology, 71, 1020-1036.

SANNA, L. J. (2000). Mental simulation, affect, and personality: A conceptual framework. Current Directions in Psychological Science, 9, 168-173.

Sanna, L. J., \& Schwarz, N. (in press). Debiasing the hindsight bias: The role of accessibility experiences and (mis)attributions. Journal of Experimental Social Psychology.

Sanna, L. J., Schwarz, N., \& Stocker, S. L. (2002). When debiasing backfires: Accessible content and accessibility experiences in debiasing hindsight. Journal of Experimental Psychology: Learning, Memory, \& Cognition, 28, 497-502.

Sanna, L. J., Stocker, S. L., \& Clarke, J. A. (in press). Rumination, imagination, and personality: Specters of the past and future in the present. In E. C. Chang \& L. J. Sanna (Eds.), Virtue, vice, and personality: The complexity of behavior. Washington, DC: American Psychological Association.

Sanna, L. J., Turley-Ames, K. J., \& Meier, S. (1999). Mood, self-esteem, and simulated alternatives: Thought-provokingaffective influences on counterfactual direction. Journal of Personality \& Social Psychology, 76, 543-558.

SCHWARZ, N. (1990). Feelings as information: Informational and motivational functions of affective states. In E. T. Higgins \& R. M. Sorrentino (Eds.), Handbook of motivation and cognition: Foundationsof social behavior (Vol. 2, pp. 527-561). New York: Guilford.

SCHWARZ, N. (1998). Accessible content and accessibility experiences: The interplay of declarative and experiential information in judgment. Personality \& Social Psychology Review, 2, 87-99.

Schwarz, N. (2002). Feelings as information: Moods influence judgments and processing strategies. In T. Gilovich, D. Griffin, \& D. Kahneman (Eds.), New perspectives on judgmentunder uncertainty (pp. 534547). Cambridge: Cambridge University Press.

Schwarz, N., Bless, H., Strack, F., Klumpp, G., RittenauerSchatKa, H., \& SimONS, A. (1991). Ease of retrieval as information: Another look at the availability heuristic. Journal of Personality \& Social Psychology, 61, 195-202.

Schwarz, N., \& Clore, G. L. (1996). Feelings and phenomenal experiences. In E. T. Higgins \& A. Kruglanski (Eds.), Social psychology: Handbook of basic principles (pp. 433-465). New York: Guilford. SchWARZ, N., \& VAUGHN, L. A. (2002). The availability heuristic revisited: Recalled content and ease of recall as information. In T. Gilovich, D. Griffin, \& D. Kahneman (Eds.), Heuristics and biases: The psychology of intuitive judgment (pp. 103-119). Cambridge: Cambridge University Press.

SkURNik, I., SchWarz, N., \& Winkielman, P. (2000). Drawing inferences from feelings: The role of naive beliefs. In H. Bless \& J. P. Forgas (Eds.), The message within: The role of subjective experience in social cognition and behavior (pp. 162-175). Philadelphia, PA: Psychology Press.

Slovic, P., \& Fischioff, B. (1977). On the psychology of experimental surprises. Journal of Experimental Psychology: Human Perception \& Performance, 3, 544-551.

StAhlberg, D., \& MAass, A. (1998). Hindsight bias: Impaired memory or biased reconstruction? European Review of Social Psychology, $\mathbf{8}$, 105-132.

Stepper, S., \& Strack, F. (1993). Proprioceptive determinants of emotional and nonemotional feelings. Journal of Personality \& Social Psychology, 64, 211-220.

Strack, F., \& Neumann, R. (2000). Furrowing the brow may undermine perceived fame: The role of facial feedback in judgments of celebrity. Personality \& Social Psychology Bulletin, 26, 762-768.

Tversky, A., \& Kahneman, D. (1973). Availability: A heuristic for judging frequency and probability. Cognitive Psychology, 5, 207-232. Wasserman, D., Lempert, R. O., \& Hastie, R. (1991). Hindsight and causality. Personality \& Social Psychology Bulletin, 17, 30-35.

Winer, B. J., Brown, D. R, \& Michels, K. M. (1991). Statistical principles and experimental design (3rd ed.). New York: McGraw-Hill.

Winkielman, P., \& Schwarz, N. (2001). How pleasant was your childhood? Beliefs about memory shape inferences from experienced difficulty of recall. Psychological Science, 12, 176-179.

Winkielman, P., Schwarz, N., \& Belli, R. F. (1998). The role of retrieval and attribution in memory judgments: Judging your memory as worse despite recalling more events. Psychological Science, 9, 124-126.

Winkielman, P., Schwarz, N., Reber, R., \& Fazendeiro, T. (in press). Cognitive and affective consequences of visual fluency: When seeing is easy on the mind. In R. Batra \& L. Scott (Eds.), Visual persuasion. Mahwah, NJ: Erlbaum. 


\section{NOTES}

1. Similar reconstruction accounts have been offered for a related phenomenon, namely, people's tendency to misremember their original answers to almanac questions as having been closer to the correct answer than was the case, once the correct answer is known (Erdfelder \& Buchner, 1998; Hoffrage, Hertwig, \& Gigerenzer, 2000; Stahlberg \& Maass, 1998). This parallels the observation that people misremember their predictions as having been closer to the actual outcome of historic events. In the present article, we focus mainly on retrospective judgments of outcome probabilities and do not specifically address almanac questions.

2. Pilot testing and prior research (Sanna et al., 2002) indicate that whether participants were told that either the British or the Gurkhas had ultimately won the war did not qualify results, so all read simply that the British had won. In addition, the participants who were not given any outcome information estimated the probability of each combatant's winning at about $50 \%$, a finding that was further reinforced by our results in the no-outcome condition of Experiment 2.

3. In the absence of facial expression manipulations, pilot testing indicated that generating five thoughts was of intermediate difficulty, a finding reinforced by subjective difficulty ratings in the control-face conditions of Experiment 2 (i.e., $M=4.52$ on a 7-point scale).

(Manuscript received April 29, 2002; revision accepted for publication July 30,2002.) 